Non-Visual Saccadic Eye Movement Rate as a Cue to Deceit

\author{
Aldert Vrij ${ }^{1}$ \\ João Oliveira \\ Annie Hammond \\ University of Portsmouth, Psychology Department \\ Howard Ehrlichman
}

Queens College of the City University of New York

\footnotetext{
${ }^{1}$ Correspondence concerning this article should be addressed to Aldert Vrij, University of Portsmouth, Psychology Department, King Henry Building, King Henry 1 Street, PO1 2DY, Portsmouth, UK or via email: aldert.vrij@ port.ac.uk
} 


\begin{abstract}
In the present experiment we considered a cue that has not been examined in nonverbal deception research before, non-visual saccadic eye movement rate. The psychological process as to why saccadic eye movements could be related to deception is also new for nonverbal deception research: memory retrieval. Non-visual saccadic eye movement rate has been shown to be related to memory search, with searching information in longterm memory generating increased saccadic activity (Ehrlichman \& Micic, 2012). According to fMRI research lying is associated with more long-term memory search than truth telling (Ganis et al., 2003), which leads to our hypothesis that liars display more saccadic eye movements than truth tellers. Thirty participants expressed a true opinion and lied about another opinion (within-subjects design) and the number of saccades per second of speech were measured. As predicted, participants displayed fewer saccades when they told the truth than when they told a spontaneous lie. The implications for this finding are discussed.
\end{abstract}




\section{Non-Visual Saccadic Eye Movement Rate as a Cue to Deceit}

People often pay a lot of attention to nonverbal behaviors when attempting to detect deceit (Vrij, 2008a). Nonverbal behaviors stand a better chance to become diagnostic cues to deceit when there is a sound theoretical underpinning as to why such behaviors should be related to deception. In the present experiment we considered a cue that has not been previously examined in nonverbal deception research and that has a strong theoretical underpinning: frequency of spontaneous non-visual saccadic eye movements. Non-visual saccades are correlated with search for information in longterm memory, with a more intensive search resulting in more saccades (Ehrlichman \& Micic, 2012). In the current paper we argue that lying involves more intensive longterm memory search than truth telling and that, consequently, liars would display more saccades than truth tellers.

Non-visual saccades differ from the eye movements typically examined in deception research. Deception researchers have examined visual saccadic eye movements related to deception, which are eye movements that change the direction of people's visual attention (from an interviewer to an object; from one picture to another, from one visually-presented word to another, etc.). None of the deception studies have involved spontaneous saccadic eye movements that occur when people are not examining a visual stimulus array.

Virtually all research on saccadic eye movements is related to their role in vision. However, saccadic eye movements also occur when people are not inspecting a visual scene, and often without the person being aware of making such movements. 
These movements occur when people are engaged in tasks that require search through long-term memory. The evidence for this, and the rationale for labeling such eye movements "non-visual," comes from numerous studies in which eye movements have been recorded as people carry out various cognitive tasks that do not involve any visual stimuli in face-to-face situations, when people are alone in a physically barren environment, when they are in complete darkness and when their eyes are closed. There is extensive research demonstrating that saccades are highly related to the efficiency of searching for information in long-term memory (LTM). Tasks that involve more difficult retrieval of information from either semantic (e.g., "Say as many words as you can that begin with the letter A") or episodic memory (e.g., recalling words from a previously learned list) typically produce about twice as many saccades per unit time (eye movement rate, EMR) as tasks that involve more easy retrieval of highly overlearned material (e.g., the alphabet, someone's name or address) or tasks that involve working memory (e.g., keeping track of a series of letters and reporting how many have a long E sound) (Bergstrom \& Hiscock, 1988; Ehrlichman, Micic, \& Zhu, 2007; Micic, Ehrlichman, \& Chen, 2010; Micic \& Ehrlichman, 2012).

When people answer questions that do not involve highly over-learned material they need to engage in a search for material in LTM. The difficulty of such a search, at least in part, reflects the number and integration of potential retrieval cues that are available. Therefore, we would expect that lying ought to be more difficult than telling the truth because lies are constructed from less readily accessible semantic and episodic information stored in memory, whereas truthful information is more readily accessible in 
LTM , as fMRI research has shown (Ganis, Kosslyn, Stose, Thompson, \& YurgelunTodd, 2003),

People sometimes prepare their lies. One could argue that prepared lies should be readily available and all that liars need to do is to tell a rehearsed story. However, the degree to which search is required would hinge on how well-prepared or rehearsed the lie is. If the person simply thought about some things to say but did not actually commit a complete script to memory, there should still be a need for some search through LTM, and some accompanying eye movements. On the other hand, if the lie is a completely overlearned word for word script, little LTM search would be required and we would expect an eye movement rate similar to the low-retrieval tasks of previous studies. Yet, fMRI research has demonstrated that, in terms of brain activity, telling a planned lie shows some overlap with telling a spontaneous lie, and differs from telling the truth in that a planned lie is more difficult to retrieve from LTM than the truth (Ganis et al., 2003). To explain this, Ganis et al. (2003) argued that truths, more than lies, are based on extensive and frequent interactions with the real world, and therefore truths are more readily accessible from LTM than planned lies. Based on Ganis et al.'s (2003) fMRI findings and given the relationship between EMR activity and high-retrieval tasks we thus predicted that truths would result in the lowest EMR activity and spontaneous lies in the highest EMR activity (Hypothesis 1). We did not predict EMR activity in planned lies as EMR activity would depend on how well-prepared or rehearsed the lie is.

Most deception research and most police/suspect interviews focus on the ability to distinguish between truth tellers and liars when they describe alleged past activities 
(Vrij, 2008b). This was not the focus of the present experiment as the relation between past activities and memory retrieval is complex, as we will argue in the Discussion. In this experiment we instructed participants to lie about their opinions. Determining the veracity of opinions can be important, for example in security settings, as demonstrated by the loss of seven CIA agents in Afghanistan on 30 December 2009. They were killed via a suicide attack by a man they believed was going to give them information about Taliban and al-Qaeda targets in Pakistan's tribal areas. The CIA was aware that the man had posted extreme anti-American views on the internet, but believed these to be part of a cover (Leal, Vrij, Mann, \& Fisher, 2010). Telling the truth or lying about opinions differs in terms of memory retrieval. People normally think more deeply about, and are more able to generate, reasons that support rather than oppose their beliefs (Ajzen, 2001). Truthful opinions should therefore be more readily available from LTM than deceptive opinions.

Apart from EMR we also measured answer duration and response difficulty. Since participants in the prepared lie condition were given time in advance to generate their answers we predicted that the planned lies would be longer in duration than truths and spontaneous lies (Hypothesis 2). We further predicted that afterwards participants would report that telling a spontaneous lie was more difficult than telling a planned lie or the truth (Hypothesis 3).

\section{Method}

\section{Participants}


Thirty undergraduate students took part in the experiment, 9 males and 21 females, with an average age of $\mathrm{M}=20.8(\mathrm{SD}=4.4)$. Participants were recruited via posters, leaflets, and online advertisements on the University's staff and student portals. Participants were invited to take part in a study "measuring opinions and attitudes about key issues going on in the world" (they were not told that this was a deception study). The advert provided contact details and offered a goody bag to those who took part.

\section{Design}

The experiment involved a within subjects design with three Veracity levels (truth, planned lie and spontaneous lie). The dependent variables were honesty ratings, EMR, answer duration and difficulty ratings.

\section{Procedure}

The experiment consisted of three phases: an Opinions Questionnaire, an interview and a post-interview questionnaire.

Phase 1. After consenting to the study, each participant completed an Opinions Questionnaire which asked the extent to which he or she agreed or disagreed (where $1=$ agree and $7=$ disagree) with the 19 different statements listed in Appendix 1 . The final question asked the participant to indicate on a 7-point scale, from [1] dishonest to [7] honest, how truthful s/he was while completing the Opinion Questionnaire. Twentyeight participants circled the maximum score ' 7 ' and the remaining two participants circled ' 6 '. 
The experimenter then selected one attitude that the participant scored 1,2,6 or 7 and inverted the score ( 7 becoming a 1, etc) - this would become the planned lie. Unknown to the participant, the experimenter also selected two further attitudes (one's score was inverted -this would become the spontaneous lie - and the other score was left untouched). Appendix 1 reveals that 14 different opinions were introduced in the truth condition and 16 different opinions in the planned and spontaneous lie conditions. This indicates a good spread of opinions in all three conditions.

The participant was then introduced to the planned lie. The participant was told which attitude was selected and that the experimenter had inverted their score on this item with a 2 becoming a 6 , a 7 becoming a 1 etc. The participant was told that he or she should say in the interview that this inverted score reflected his or her real attitude. The participant was then told that the interviewer would ask the following question "I understand you are in favor of/against <attitude>. Is this true?" and that the participant should say YES to this question and thereby tell a lie. The participant was then informed that the interviewer would ask as a second question "Explain with as much detail as you can why you have this opinion". The participant was asked to think about reasons why people could hold this attitude, to write them down, to rehearse them, and to recall them during the interview as being his or her true opinion. To give the participant an opportunity to think about the planned lie, the experimenter left the room. The experimenter returned to the room five minutes later and after the participant said that s/he finished planning the lie, the experimenter said: "Remember your answer because this attitude will be discussed during the interview, and you will have to lie about it, just as we discussed. There will be two other attitudes discussed during the 
interview but I cannot tell you which ones. You always have to answer YES to the question "I understand you are in favor/against <attitude>. Is this true?". For one attitude, this YES answer is your true opinion and you thus can be truthful when answering the second question (Explain with as much detail as you can why you have this opinion). For the other attitude, this YES answer contradicts your true opinion, and you thus have to lie when answering the second question. You should try to ensure that the interviewer believes that you express your true opinion to each question asked during the interview." The experimenter then brought the participant to the interview room.

Phase 2. When the participant prepared reasons for the prepared lie (no time limit was given for this), the experimenter went to see the interviewer and gave him the three selected attitudes and the order in which they needed to be discussed. The interviewer was blind to the ground truth and did not know the participant's true attitude towards any of the three selected attitudes.

During the interview the interviewer discussed the three selected attitudes with each participant, each time by asking the two questions presented above. Each participant told the truth once and lied twice. One of these lies was the lie the participant was told about earlier (planned lie). The other lie, about which the participant had no prior knowledge, was the spontaneous lie. The order of truth telling, and telling spontaneous and planned lies was counterbalanced.

The participant sat in a chair facing a webcam at eye level. The webcam was positioned on a table in such a way that the participant's entire face was visible. There 
were three more tables in the room, not visible to the participant while sitting down, and a turned off TV in the corner. The interviewer sat to the right of the participant behind the computer which recorded the interview, and the participant had no direct line of sight to the interviewer. The participant was instructed to look ahead at all times during the entire interview

Phase 3. After the interview each participant completed a questionnaire consisting of six questions. The questionnaire asked to indicate in percentages (i) how honest the participant was when discussing each of the three attitudes $(0 \%$ - dishonest to $100 \%$ - honest), and (ii) how difficult it was to discuss each of the three attitudes ( $0 \%$ easy to $100 \%$ - difficult). The post-interview questionnaire also asked participants to guess what the aim of the study was; no-one thought it was measuring eye movements.

\section{Coding}

We counted all saccadic eye movements that the participant made in the period between the interviewer finishing asking the question and the participant finishing answering the question. An expert coder, blind to the experimental conditions, rated each saccadic eye movement off-line using a program designed for scoring saccadic eye movements from a video recording (Ehrlichman et al., 2007). The monitor was approximately $70 \mathrm{~cm}$ from the scorer. The participant's face appeared on the monitor such that the approximate diameter of an eye was $1.3 \mathrm{~cm}$. The speed of the recording was reduced to one-half real-time. The coder pressed a button on the computer keyboard whenever a saccadic eye movement was detected (defined as any observable shift of the eyes from one position to another). These parameters have been shown 
through calibration checks to enable saccadic eye movements as small as 2 to 3 deg to be clearly discernible. A second coder also coded the saccadic eye movements. The inter-rater reliability between the expert coder and second coder was very high, Intra Class Correlation Coefficient $($ ICC $)=.98$. We used the expert coder's ratings in the analyses. The number of saccadic eye movements was controlled for the answer duration (i.e., total time from the participant's initial to final utterance when responding) and the mean scores presented in this article represent the number of saccadic eye movements per second calculated over the answer duration.

\section{Results}

\section{Manipulation Check}

Table 1 about here

Honesty. A multivariate $\mathrm{F}$ test indicated that there was a significant effect of condition on eye movement rate, $F(2,28)=80.55, p<.001, \eta^{2}=.85$. Paired samples t-tests were conducted to compare honesty ratings between the three conditions. Participants reported that their truthful answers were more truthful than their spontaneous lies, $t(29)$ $=12.6, p<.001, d=2.98$, and their planned lies, $t(29)=11.3, p<.001, d=3.42$. No significant difference emerged between spontaneous lies and planned lies, $t(29)=1.0, p$ $=.34, d=.15$ (Table 1). These findings indicate that the participants adhered to the request to lie when they were instructed to do so.

\section{Hypothesis Testing}


Eye Movement Rate. First we examined the effect of the order in which the truths, spontaneous lies and planned lies were presented on eye movement rate (EMR). Order had no effect on these three EMRs, all Fs $<.55$, all p's $>.90$. A multivariate $\mathrm{F}$ test indicated that there was a significant effect of condition on eye movement rate, $F(2,28)=3.38, p=.048, \eta^{2}=.20$. Paired samples t-tests were conducted to compare eye movement rates between the three conditions. Spontaneous lies resulted in higher EMRs than truths, $t(29)=2.6, p=.013, d=0.25$, which supports Hypothesis 1 (Table 1). A frequency analysis showed that two participants displayed the same number of EMRs during their spontaneous lies and truths. After removing these inconclusive results, it was found that $68 \%$ of the participants displayed more EMRSs during spontaneous lies than during truths.

The EMR for planned lies was in between those for spontaneous lies and truths. No differences were found between spontaneous and planned lies, $t(29)=1.16, p=.25$, $d=0.23$, or between truths and planned lies, $t(29)=1.13, p=.27, d=0.20$.

Answer Duration in Seconds. A multivariate F test indicated that there was a significant effect of condition on answer duration, $F(2,28)=7.52, p=.002, \eta^{2}=.35$. Paired samples t-tests were conducted to compare the length of the answers between the three conditions. Planned lies were longer than truths, $t(29)=3.9, p=.001, d=0.80$ and spontaneous lies, $t(29)=3.0, p=.005, d=0.63$, which supports Hypothesis 2 (Table 1). No difference emerged between truths and spontaneous lies, $t(29)=.1, p=.92, d=.02$.

Difficulty. A multivariate $\mathrm{F}$ test indicated that there was a significant effect of condition on difficulty ratings, $F(2,28)=19.45, p<.001, \eta^{2}=.58$. Paired samples t-tests 
were conducted to compare difficulty ratings between the three conditions. Telling a spontaneous lie was considered to be more difficult than telling the truth, $t(29)=6.2, p$ $<.001, d=1.38$, or a planned lie, $t(29)=4.6, p<.001, d=1.06)$, supporting Hypothesis

3 (Table 1). The difficulty scores were higher in the planned lie than truth condition, but the difference was only marginally significant, $t(29)=1.7, p=.096, d=.37$.

\section{Discussion}

The relationship between non-visual saccadic eye movements and deception was examined. Participants displayed more saccadic eye movements when they told a spontaneous lie than when they told a truth. Although the difference in eye movement rate (0.13) might appear to be small, it is comparable to the difference found by Ehrlichman et al. (2007) between more and less difficult information retrieval tasks (0.14). Moreover, of the 28 out of 30 participants who displayed differences in EMRs between spontaneous lies and truths, 68\% displayed more EMRs when lying. This EMR result can be explained with the notion that telling a spontaneous lie requires more extensive LTM retrieval than truth telling (Ganis et al., 2003), and saccadic eye movements are positively related to the extent of LTM retrieval (Ehrlichman \& Micic, 2012). The number of saccadic eye movements in planned lies fell in between those for truths and spontaneous lies, and did not differ significantly from either of them. According to Ganis et al. (2003) spontaneous lies and planned lies have in common that the information required to formulate both types of lie may not be readily available in LTM. In case of a planned lie, it sounds reasonable that most investment in LTM 
retrieval takes place in the planning phase prior to the interview. This makes a planned lie less distinctive from the truth than a spontaneous lie in terms of LTM retrieval.

The planned lies were longer in duration than the truths or spontaneous lies. Perhaps preparation enabled participants to generate a detailed response, which was reflected in the length of their statements. Truths were not longer than spontaneous lies, which is surprising given that people are more able to generate reasons that support rather than oppose their views (Ajzen, 2001). We cannot explain this finding based on our analyses, and recommend future research to investigate this further.

Preparation makes lying easier (DePaulo et al., 2003; Sporer \& Schwandt, 2006; Walczyk, Igou, Dixon, \& Tcholakian, 2013). This was also the case in the present experiment, and the participants found telling the planned lie easier than telling the spontaneous lie. Moreover, participants found telling their planned lie equally difficult as telling the truth. On the one hand, someone might expect telling a rehearsed story (planned lie) to be easier than spontaneously tell the truth. On the other hand, lying involves more elements than story telling (Vrij et al., 2008), including a desire to show an honest demeanor. Carrying out multiple tasks simultaneously (story telling and making a good impression, which is what liars do) is cognitively more difficult than carrying out one task (just story telling, which is what truth tellers do), because in the former situation interviewees need to divide their attention between the multiple tasks (Johnston, Greenberg, Fisher, \& Martin, 1970; Smith, 1969). It seems that these two forces (rehearsed answers versus multi-tasking) balanced each other out. 
The literature on the relationship between eye movements and deception is substantial. Vrij (2008b) reviewed 45 published eye movement deception studies and more studies have emerged since then. Previous studies have considered the position of the eyes (i.e., making (deliberate) eye contact with a questioner, Mann et al., 2012, 2013, in press, Vrij, Mann, Leal, Fisher, 2010, averting gaze during eye contact to reduce cognitive interference, Walczyk, Griffith, Yates et al., 2013, direction of gaze shifts, Wiseman, Hatfield, Watt et al., 2012), pupil size (Webb et al., 2009), or eye movements during visual activities such as reading (Cook, Hacker, Webb et al., 2012) or viewing faces (Althoff \& Cohen, 1999). All of these studies focused on visual eye movements; none have assessed the non-visual eye movements we were interested in. We are aware of one deception study that examined non-visual saccadic eye movements, an unpublished study by Baker, Goldstein, and Stern (1992). In this small study $(\mathrm{n}=10)$ the authors looked at saccadic eye movements after the participant finished responding and was waiting for the next question. It is unclear how this relates to ongoing cognitive activity during the lie/truth response, the topic we were interested in.

It is worth noting that in the present study eye movements were not influenced by social patterns and conventions of eye contact and aversion, as the interviewer was not directly facing or looking at the participants. Nor did we tell the participants that we were interested in eye movements, unlike studies where eye movements are assessed via eye trackers. The use of eye trackers could be necessary in some eye movements research where fine-grained analysis of the speed, size or direction of the eye movements are at issue. This is not the case when assessing the frequency of saccadic 
eye movements of 2 deg or larger, as they can easily and reliably be coded with visual observation particularly when the speed of playback is reduced to one-half real-time.

Non-visual saccadic eye movements rate has never been examined in relation to deception before, and also the notion that differences between truth tellers and liars in memory retrieval can reveal a nonverbal cue to deceit is new. As is the case with all new research avenues, many questions remain unanswered. One obvious question is 'When are non-visual saccadic eye movements indicative of deception?' This experiment demonstrated that non-visual saccadic eye movements distinguish between truth tellers and liars when they discuss their opinions. The relationship between LTM retrieval and truth telling and lying is more complex when people lie about their past activities. Such lies can be well rehearsed, which would result in efficient LTM retrieval; and truth tellers may have difficulty to retrieve their information from LTM. Also, sometimes liars report a truthful memory recall but embed a lie into this report (Leins, Fisher, \& Ross, 2013; Nahari, Vrij, \& Leal, in press; Strömwall \& Willén, 2011). In such situations, are non-visual saccadic eye movements not indicative of deceit? The benefit of a theory-based lie detection method is that someone can predict when it can be used. Non-visual saccadic eye movements are likely to emerge as a cue to deceit in settings where telling the truth requires less LTM retrieval than telling a lie. Since it cannot be guaranteed that this is the case in the past activities scenarios just described, it is unlikely that non-visual saccadic eye movements will be indicative of deceit in such scenarios. A combination of theoretical reasoning and empirical research could examine if and when non-visual saccadic eye movements are indicative of deceit when people recall and report past activities. 
In the present experiment we examined unprepared and prepared lies, as well as unprepared truths, but a 'prepared truths' condition was missing. We did not include a 'prepared truths' condition in our experimental design as this is an odd condition from an applied perspective. Truth tellers typically do not prepare themselves for interviews, as they typically do not expect to be interviewed. Even when they expect to be interviewed, they often do not feel the need to prepare themselves because they 'will just tell the truth' or 'do not know what will be asked during the interview' (Hartwig, Granhag, Strömwall, \& Doering, 2010; Vrij, Mann, Leal, \& Granhag, 2010).

\section{Practical Applications}

Nonverbal behaviors stand a better chance to become diagnostic cues to deceit when there is a sound theoretical underpinning as to why such behaviors should be related to deception. Non-visual saccadic eye movements fall into this category as they are related to LTM search, with a more extensive search resulting in more saccades. Therefore, in situations where it can be expected that lying involves more LTM search than truth telling, saccades may indicate deceit. We demonstrated in this article that lying about opinions can be spotted when paying attention to saccades. Being able to detect lies when people express opinions can be important, but this type of lie has been under-researched. It can be important in investigative interviews, but also outside this domain. For example, in political debates on television, do politicians give spontaneous answers to the questions based on their beliefs and opinions or do they give wellrehearsed answers? Saccades may provide an answer, as the former answers should lead to more saccades than the latter answers. 
In sum, we demonstrated that non-visual saccadic eye movements differentiated truths from spontaneous lies when discussing opinions. Telling a spontaneous lie involves more LTM retrieval than truth telling, and, since saccades are related to LTM retrieval, spontaneous lies are associated with more saccades than truths. 


\section{References}

Ajzen, I. (2001). Nature and operation of attitudes. Annual Review of Psychology, 52, 27-58.

Althoff, R. R. and Cohen, N. J. (1999). Eye-movement-based memory effect: A reprocessing effect in face perception. Journal of Experimental Psychology: Learning, Memory and Cognition, 25, 997-1010.

Baker, L., Goldstein, R., \& Stern, J. A. (1992). Saccadic eye movements in deception. Department of Defense Polygraph Institute. www.dtic.mil/cgibin/GetTRDoc?AD=ADA304658

Bergstrom, K. J., \& Hiscock, M. (1988). Factors influencing ocular motility during the performance of cognitive tasks. Canadian Journal of Psychology, 42, 1-23.

Cook, A. E., Hacker, D. J., Webb, A.K., Osher, D., Kristjansson, S. D., Woltz, D. J., \& Kircher, J. C. (2012). Lyin' eyes: Ocular-motor measures of reading reveal deception. Journal of Experimental Psychology: Applied, 18, 301-313.

DePaulo, B. M., Lindsay, J. L., Malone, B. E., Muhlenbruck, L., Charlton, K., \& Cooper, H. (2003). Cues to deception. Psychological Bulletin, 129, 74-118.

Ehrlichman, H., \& Micic, D. (2012). Why do people move their eyes when they think? Current Directions in Psychological Science, 21, 96-100.

Ehrlichman, H., Micic, D., Sousa, A., \& Zhu, J. (2007). Looking for answers: Eye movements in non-visual cognitive tasks. Brain and Cognition, 64, 7-20. 
Ganis, G., Kosslyn, S. M., Stose, S., Thompson, W. L., \& Yurgelun-Todd, D. A. (2003). Neural correlates of different types of deception: An fMRI investigation. Cerebral Cortex, 13, $830-836$.

Hartwig, M., Granhag, P. A., Strömwall, L, \& Doering, N. (2010). Impression and information management: On the strategic self-regulation of innocent and guilty suspects. The Open Criminology Journal, 3, 10-16

Johnston, W. A., Greenberg, S. N., Fisher, R. P., \& Martin, D. W. (1970). Divided attention: A vehicle for monitoring memory processes. Journal of Experimental Psychology, 83, 164-171.

Leal, S., Vrij, A., Mann, S., \& Fisher, R. (2010). Detecting true and false opinions: The Devil's Advocate approach as a lie detection aid. Acta Psychologica, 134, 323-329.

Leins, D., Fisher, R. P., \& Ross, S. J. (2013). Exploring liars' strategies for creating deceptive reports. Legal and Criminological Psychology, 18, 141-151.

Mann, S., Ewens, S., Shaw, D., Vrij, A., Leal, S., \& Hillman, J. (2013). Lying eyes: Why liars seek deliberate eye contact. Psychiatry, Psychology, and Law, 20, 452-461.

Mann, S., Vrij, A., Leal, S., Granhag, P. A., Warmelink, L., \& Forrester, D. (2012). Windows to the soul? Deliberate eye contact as a cue to deceit. Journal of Nonverbal Behavior, $36,205-215$. 
Mann, S., Vrij, A., Nasholm, E., Warmelink, L., Leal, S., \& Forrester, D. (in press). The direction of deception: Neuro-Linguistic Programming as a lie detection tool. Journal of Police and Criminal Psychology.

Micic, D., Ehrlichman, H., \& Chen, R. (2010). Why do we move our eyes while trying to remember? The relationship between non-visual gaze patterns and memory. Brain and Cognition, 74, 210-224.

Nahari, G., Vrij, A., \& Leal, S. (in press). Did somebody see it? Applying the verifiability approach to insurance claims interviews. Journal of Investigative Psychology and Offender Profiling.

Smith, M. C. (1969). Effect of varying channel capacity on stimulus detection and discrimination. Journal of Experimental Psychology, 82, 520-526.

Sporer, S. L., \& Schwandt, B. (2006). Paraverbal indicators of deception: A meta-analytic synthesis. Applied Cognitive Psychology, 20, 421-446.

Strömwall, L. A., \& Willén, R. (2011). Inside criminal minds: Offenders'strategies when lying. Journal of Investigative Psychology and Offender Profiling, 8, 271-281. DOI: $10.1002 /$ jip.148

Vrij, A. (2008a). Nonverbal dominance versus verbal accuracy in lie detection: A plea to change police practice. Criminal Justice and Behavior, 35, 1323-1336.

Vrij, A. (2008b). Detecting lies and deceit: Pitfalls and opportunities, second edition. Chichester: John Wiley and Sons. 
Vrij, A., Mann, S., Fisher, R., Leal, S., Milne, B., \& Bull, R. (2008). Increasing cognitive load to facilitate lie detection: The benefit of recalling an event in reverse order. Law and Human Behavior, 32, 253-265.

Vrij, A., Mann, S., Leal, S., \& Fisher, R. (2010). 'Look into my eyes': Can an instruction to maintain eye contact facilitate lie detection? Psychology, Crime, \& Law, 16, 327-348.

Vrij, A., Mann, S., Leal, S., \& Granhag, P. A. (2010). Getting into the minds of pairs of liars and truth tellers: An examination of their strategies. The Open Criminology Journal, 3, 17-22 (special issue on deception research).

Walczyk, J. J., Griffith, D. A., Yates, R., Visconte, S., \& Sinoneaux, B. (2013). Eye movements and other cognitive cues to rehearsed and unrehearsed deception when interrogated about a mock crime. Applied Psychology in Criminal Justice, 9, 1-23.

Walczyk, J. J., Igou, F. P., Dixon, A. P., \& Tcholakian, T. (2013). Advancing lie detection by inducing cognitive load on liars: A review of relevant theories and techniques guided by lessons from polygraph-based approaches. Frontiers in Psychology, 4, 14. DOI 10.3389/fpsyg.2013.00014.

Webb, A. K., Hacker, D. J., Osher, D., Cook, A. E., Woltz, D. J., Kristjansson, S., \& Kircher, J. C. (2009). Eye Movements and Pupil Size Reveal Deception in Computer Administered Questionnaires. Foundations of Augmented Cognition. Neuroergonomics and Operational Neuroscience, 5638, 553-562. 
Wiseman, R., Hatfield, H.R.T., Watt, C., ten Brinke, L., Porter, S., Couper, S-L., \& Rankin, C. (2012). The eyes don't have it: Lie detection and neuro-linguistic programming. PLoS ONE, 7, ArtIDe40259. 
Table 1. Honesty Ratings, EMR, Answer Duration and Difficulty Ratings as a Function of Veracity

\begin{tabular}{lcccccc}
\hline & \multicolumn{2}{c}{ Truth } & \multicolumn{2}{c}{ Planned Lie } & \multicolumn{2}{c}{ Spontaneous lie } \\
\cline { 2 - 7 } & $M$ & $S D$ & $M$ & $S D$ & $M$ & $S D$ \\
\hline Honesty in percentages & $93.67^{\mathrm{b}}$ & 17.71 & $17.00^{\mathrm{a}}$ & 27.07 & $21.33^{\mathrm{a}}$ & 30.88 \\
EMR & $.63^{\mathrm{a}}$ & .46 & $.69^{\mathrm{ab}}$ & .53 & $.76^{\mathrm{b}}$ & .56 \\
& & & & & & \\
Duration in seconds & $23.57^{\mathrm{a}}$ & 13.78 & $33.48^{\mathrm{b}}$ & 20.52 & $23.83^{\mathrm{a}}$ & 16.99 \\
& & & & & & \\
Difficulty in percentages & $19.00^{\mathrm{a}}$ & 33.41 & $31.00^{\mathrm{a}}$ & 31.36 & $65.33^{\mathrm{b}}$ & 33.60
\end{tabular}

Note: Only different mean scores in rows with a different superscript differ significantly ( $p$ $<.05)$ from each other 
Appendix 1. Opinions Used in the Experiment and the Number of Participants that was Interviewed about Each Opinion in Each of the Three Experimental Conditions

\begin{tabular}{|c|c|c|c|}
\hline & Truth & $\begin{array}{l}\text { Planned } \\
\text { lie }\end{array}$ & $\begin{array}{l}\text { Rehearsed } \\
\text { lie }\end{array}$ \\
\hline 1-Abortion is morally acceptable & 4 & 5 & 1 \\
\hline 2-The death penalty should be used in the UK. & 6 & 1 & 1 \\
\hline 3-Community Support Officers are necessary. & 2 & 2 & 0 \\
\hline $\begin{array}{l}\text { 4-Gay couples should be allowed to marry in the } \\
\text { UK. }\end{array}$ & 3 & 3 & 3 \\
\hline $\begin{array}{l}\text { 5-A Muslim woman should be allowed to wear a } \\
\text { veil whenever she wants }\end{array}$ & 1 & 2 & 1 \\
\hline 6-Cannabis should be legalized in the UK & 3 & 1 & 3 \\
\hline $\begin{array}{l}\text { 7-Gypsies should be made to have permanent } \\
\text { homes. }\end{array}$ & 0 & 2 & 2 \\
\hline $\begin{array}{l}\text { 8-There should be a ban on smoking in public } \\
\text { places. }\end{array}$ & 1 & 4 & 0 \\
\hline 9-Pirating DVD's should be legal. & 2 & 1 & 3 \\
\hline $\begin{array}{l}\text { 10-Euthanasia should be legal for the terminally ill } \\
\text { in the UK. }\end{array}$ & 1 & 2 & 2 \\
\hline $\begin{array}{l}\text { 11-Gay couples should not be allowed to adopt } \\
\text { children }\end{array}$ & 0 & 0 & 3 \\
\hline $\begin{array}{l}\text { 12-Terrorist suspects should be detained for as long } \\
\text { as necessary. }\end{array}$ & 0 & 1 & 1 \\
\hline 13-Animals should not be used in medical research. & 3 & 1 & 2 \\
\hline $\begin{array}{l}\text { 14-People who avoid paying taxes should be jailed } \\
\text { and have to pay the full amount back.. }\end{array}$ & 0 & 1 & 1 \\
\hline $\begin{array}{l}\text { 15-There should an enforced uniform for students } \\
\text { attending university. }\end{array}$ & 1 & 1 & 1 \\
\hline 16-Telling children that Santa Claus is real is fine. & 1 & 1 & 2 \\
\hline
\end{tabular}




\begin{tabular}{|l|c|c|c|}
\hline $\begin{array}{l}\text { 17-The adoption of children from third world } \\
\text { countries by celebrities is good for the child. }\end{array}$ & 0 & 2 & 0 \\
\hline 18-The invasion of Iraq was necessary. & 1 & 0 & 3 \\
\hline $\begin{array}{l}\text { 19-The minimum age for drinking alcohol in the UK } \\
\text { should be increased. }\end{array}$ & 1 & 0 & 1 \\
\hline
\end{tabular}

